Research Article

\title{
Reliability Analysis of a Direct Shear Test of Modified Iron Tailings Based on the Monte Carlo Algorithm
}

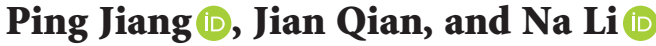 \\ School of Civil Engineering, Shaoxing University, Shaoxing 312000, China \\ Correspondence should be addressed to Na Li; lina@usx.edu.cn
}

Received 24 August 2020; Revised 24 September 2020; Accepted 23 October 2020; Published 16 November 2020

Academic Editor: Yong Liu

Copyright (c) 2020 Ping Jiang et al. This is an open access article distributed under the Creative Commons Attribution License, which permits unrestricted use, distribution, and reproduction in any medium, provided the original work is properly cited.

The resource utilization of iron tailings is of great significance for all countries in the world. Considering the particle composition and physicochemical characteristics of iron tailings, fiber and lime were used to modify iron tailings. The fiber content was $0 \%, 0.25 \%, 0.5 \%, 0.75 \%$, and $1 \%$, and the lime content was $0 \%, 2 \%, 4 \%, 8 \%$, and $10 \%$, respectively. Through a direct shear test, the shear stress displacement $(\tau-\delta)$ curves and shear strength of modified iron tailings, under the action of a 0 freeze-thaw cycle and 1 freeze-thaw cycle, were tested. As statistics have shown that there are uncertainty factors associated with direct shear tests, the shear strength index cohesion $c$ and internal friction angle $\varphi$ of the modified iron tailings were analyzed using the Monte Carlo method. The results show that the $\tau$ - $\delta$ curve of the fiber-modified iron tailings is a hardening-type curve and that of the lime-modified iron tailings is a softening-type curve. In the direct shear tests, the main uncertain factors are the specimen diameter, vertical force, and horizontal force. The diameter of the sample obeys a normal distribution, and the vertical and horizontal forces obey a uniform distribution. The results of the Monte Carlo simulation show that both $c$ and $\varphi$ obey a normal distribution. Under a 95\% confidence condition, the effect of fiber on the cohesion on iron tailings is obvious, but the effect on the internal friction angle is not obvious. However, the values of $c$ and $\varphi$ of the iron tailings are clearly improved by lime. Additionally, the iron tailings modified by a fiber content of $1 \%$ and those modified by a lime content of $8 \%$ have the best frost resistance.

\section{Introduction}

With the development and utilization of mineral resources, a large number of tailings have been produced. Since the implementation of the reform and opening-up policy, especially, with the rapid development of China's iron and steel industry, iron tailings are increasingly produced by the development of iron ore resources. For example, Shaoxing has produced 20 million tons of iron tailings. Not only do these iron tailings occupy a large number of land resources, but the heavy metals in them also pollute the environment [1-3]. Therefore, the recovery and utilization of tailings are of great significance for all countries in the world.

However, iron tailings have the defects of high compressibility, high water content, low permeability, and low strength [4], and they therefore cannot be used directly. Thus, in recent years, scholars have conducted a lot of research on the use of iron tailings as building materials. They are mainly used in the preparation of cementitious materials [5], Portland cement clinker [6], concrete fine aggregate [7-11], concrete mineral admixture [12], mortar for laying and coating [13], road materials $[14,15]$, etc., and have achieved good results.

However, the research on iron tailings as the main building materials is less widespread, which restricts the resource utilization of iron tailings to a certain extent. For example, Wang et al. [16] studied the mechanical properties of tailing sand under the condition of dry and wet cycles. The results show that the water characteristic curve of tailing sand tends to move to the left with the increase of dry and wet cycles, which provides a basis for understanding the mechanical properties of tailing sand and the stability of tailing dams under the condition of dry and wet cycles. Jiang et al. [17] used a direct shear test and energy dissipation 
theory to study the shear performance of lime-modified iron tailing powder. The research shows that adding lime can improve the shear energy consumption of iron tailing powder, and, with the increase of the lime content, the shear energy consumption first increases and then decreases. Chen et al. [18] studied the anisotropic shear strength characteristics of tailing sand. The results show that the anisotropy has a great influence on the peak shear strength of tailing sand and a minor influence on the peak internal friction angle. Chen et al. [19] studied the relationship between the resistivity and shear strength of phosphorus tailings. The results show that the initial resistivity of phosphorus tailings is negatively related to the cohesion and internal friction angle of the shear strength index, while the resistivity decreases with the increase of the strain. The above research shows that it is difficult to produce iron tailings with mechanical properties that meet the engineering requirements, so they need to be modified.

Adding fiber and lime is a common engineering modification method [20-22]. Combined with the physical and chemical properties of iron tailings, fiber and lime are used to modify iron tailings, and the shear property under the action of a freeze-thaw cycle is an important mechanical property of building materials. Therefore, according to the Mohr-Coulomb theory, a direct shear test can be used to study the shear mechanical index cohesion $c$ and the internal friction angle $\varphi$ of the modified iron tailings. The uncertain factors associated with direct shear tests often affect the accuracy of the test results. Additionally, the shear strength of the soil is one of the basic parameters in analyzing and solving the stability of geotechnical engineering [23-29]. The randomness of test data will affect the stability analysis results [30-32]. To make the direct shear test results more reliable, it is necessary to carry out statistical analysis on the uncertain factors associated with direct shear tests and then obtain the change rule of $c$ and $\varphi$ of the modified iron tailings.

The Monte Carlo algorithm is a mathematical method that can produce a large number of data results, without any physical experiments. This method can directly consider the probability distribution of any type of random variables and can calculate the probability characteristics of parameters with the expected accuracy [33]. Moreover, the calculation principle and operation method of the Monte Carlo algorithm are simple and have a high calculation accuracy. Direct shear test is a basic test method to obtain mechanical parameters of rock and soil materials [34]. However, due to the randomness of specimen size and stress test, it is significant to analyze the influence of these random processes on the results of the direct shear test. The Monte Carlo simulation of the direct shear test can effectively reduce the amount of the test and save the test cost $[35,36]$. It is feasible to analyze the direct shear properties of fiber and limemodified iron tailings by the Monte Carlo method. In this paper, through a statistical analysis of the uncertainty factors associated with direct shear tests, the Monte Carlo algorithm is used to analyze the shear strength indexes $c$ and $\varphi$ of the modified iron tailings, so as to provide a basis for the resource utilization of tailings.

\section{Direct Shear Test}

2.1. Materials. The test material is iron tailings from Lizhu iron tailings pond, Zhejiang Province, China. Its main components are $\mathrm{SiO}_{2}, \mathrm{Fe}_{2} \mathrm{O}_{3}, \mathrm{Al}_{2} \mathrm{O}_{3}, \mathrm{CaO}$, and $\mathrm{MgO}$. Its specific gravity is 3.06 and the specific surface area is $379 \mathrm{~m}^{2} / \mathrm{kg}$. The fiber used is polypropylene fiber with a diameter of $30 \mu \mathrm{m}$ and a length of $6 \mathrm{~mm}$. The lime used is quicklime with a calcium content of $90 \%$.

2.2. Test Scheme. In this study, fiber and lime are used to modify iron tailings, and 0 freeze-thaw and 1 freeze-thaw direct shear tests are carried out. The test scheme is shown in Table 1. P0 in the table represents no freeze-thaw cycle, and P1 represents one freeze-thaw cycle. $F$ stands for fiber, and $L$ stands for lime.

2.3. Test Process. According to the standard for soil test methods (GBT50123-2019) [37], the direct shear test process is divided into the following steps:

(1) According to the test plan, polypropylene fiber and lime with different contents are added to iron tailings and fully mixed to obtain the mixture.

(2) A layer of Vaseline is applied to the inner side of the ring cutter with a diameter of $61.8 \mathrm{~mm}$ and a height of $20 \mathrm{~mm}$, the mixture is put into the ring cutter, and the sample is then compacted to form.

(3) The sample is wrapped with fresh-keeping film, and according to the test plan, the sample is placed, without a freeze-thaw cycle, in the room for 24 hours, and the freeze-thaw sample is put into the freeze-thaw box for one freeze-thaw cycle. The freeze-thaw cycle conditions are as follows: $-20^{\circ} \mathrm{C}$ and 24 hours, and $20^{\circ} \mathrm{C}$ and 24 hours.

(4) After curing, the sample is taken out, and the mass of each sample is weighed. The mass is $142 \pm 2 \mathrm{~g}$.

(5) A direct shear test is carried out, and the test equipment is a fully-automatic four-way direct shear apparatus. From each group of tests, 4 samples are taken and put into a shear box for fixation, and the shear test is carried out under 4 different vertical pressures. The vertical pressure is $100 \mathrm{kPa}, 200 \mathrm{kPa}$, $300 \mathrm{kPa}$, and $400 \mathrm{kPa}$.

2.4. Test Results. According to the results of the direct shear test, the $\tau$ - $\delta$ curves obtained from each group of data, under the same normal stress, are placed in the same image. The image of the $\tau-\delta$ curves with the 0 freeze-thaw cycle is shown in Figure 1, and the image of the $\tau-\delta$ curves with the 1 freezethaw cycle is shown in Figure 2.

From Figure 1, it can be seen that the $\tau-\delta$ curve of the fiber-modified iron tailings with the 0 freeze-thaw cycle is a hardening-type curve, and the stress peak occurs when the shear displacement reaches $4 \mathrm{~mm}$. The $\tau$ - $\delta$ curve of the limemodified iron tailing with the 0 freeze-thaw cycle is a softening-type curve. With the increase of the shear 
TABle 1: Test scheme.

\begin{tabular}{|c|c|c|c|c|c|}
\hline \multicolumn{3}{|c|}{0 freeze-thaw cycle } & \multicolumn{3}{|c|}{ One freeze-thaw cycle } \\
\hline Fiber content $(\%)$ & Fiber content $(\%)$ & Number & Fiber content $(\%)$ & Fiber content $(\%)$ & Number \\
\hline 0 & 0 & P0-0-0 & 0 & 0 & P1-0-0 \\
\hline 0.25 & 0 & P0-F-1 & 0.25 & 0 & P1-F-1 \\
\hline 0.5 & 0 & $\mathrm{P} 0-\mathrm{F}-2$ & 0.5 & 0 & P1-F-2 \\
\hline 0.75 & 0 & P0-F-3 & 0.75 & 0 & P1-F-3 \\
\hline 1 & 0 & $\mathrm{P} 0-\mathrm{F}-4$ & 1 & 0 & P1-F-4 \\
\hline 0 & 2 & P0-L-1 & 0 & 2 & P1-L-1 \\
\hline 0 & 4 & P0-L-2 & 0 & 4 & P1-L-2 \\
\hline 0 & 8 & P0-L-3 & 0 & 8 & P1-L-3 \\
\hline 0 & 10 & P0-L-4 & 0 & 10 & P1-L-4 \\
\hline
\end{tabular}

displacement, the shear stress first increases to the peak value and then decreases gradually, and with the increase of the normal stress, the maximum shear stress increases gradually.

From Figure 2, it can be seen that the $\tau-\delta$ curves of the fiber-modified iron tailings and lime-modified iron tailings with one freeze-thaw cycle have the same curve characteristics as those shown in Figure 1. However, the maximum shear stress with the one freeze-thaw cycle is lower than that with the 0 freeze-thaw cycle.

The peak shear stress $\tau_{\max }$ for each $\tau$ - $\delta$ curve in Figures 1 and 2 is extracted. According to the Mohr-Coulomb criterion, the cohesion $c$ and internal friction angle $\varphi$ of each group of samples can be obtained, as shown in Table 2 .

It can be seen, from Table 2, that, under the action of the 0 and 1 freeze-thaw cycles, the effect of fiber on the cohesion on iron tailings is obvious, but the internal friction angle is not obvious. However, the cohesion and internal friction angle of the iron tailings are clearly improved by lime.

\section{Monte Carlo Simulates the Process of a Direct Shear Test}

There is some uncertainty associated with direct shear tests. The values of $c$ and $f$ calculated in Figures 1 and 2 cannot easily represent the actual law. Therefore, the Monte Carlo algorithm is used to fit the uncertainty in the process of the direct shear test, and the statistical rules of $c$ and $f$ of the modified iron tailings are obtained.

The process of the Monte Carlo algorithm is mainly divided into three steps [38]. (1) The probability distribution characteristics of the uncertain parameters are analyzed in a random process, and a mathematical model of the probability distribution is established. (2) According to the probability distribution model of the parameters, random numbers are generated. (3) According to the accuracy requirements, the number of simulations is determined. The random number is sampled randomly for each simulation, and the target parameter value is calculated. Finally, the probability distribution characteristics and confidence intervals of the target parameters are calculated. The flow chart of the random process in the simulated direct shear test is shown in Figure 3.

3.1. Parameter Distribution Model. There are three main factors influencing the results of the direct shear test: the vertical force $F$, horizontal force $T$, and specimen diameter $d$.
According to the instructions of the direct shear apparatus used in the test, the force value error of the apparatus is $5 \%$, which is the relative error, and it obeys a uniform distribution. Then, the probability distribution of the vertical force $F$ is shown in

$$
F \sim U(F-0.05, F+0.05 F)
$$

Similarly, the horizontal force $T$ also obeys a uniform distribution, so the distribution of the horizontal force $T$ is shown in

$$
T \sim U(T-0.05 T, T+0.05 T) .
$$

The diameter of the direct shear specimen was repeatedly measured 100 times with a Vernier caliper, and 100 diameter data were obtained. Although the variation range of the random measurement error is small, the error range of direct shear test results may be enlarged after calculation. Therefore, it is necessary to generate more random numbers from less data by the Monte Carlo method, which is convenient for subsequent calculation [39]. As the random measurement error follows a normal distribution [40, 41], the cumulative distribution curve of the diameter and the fitted normal distribution curve are obtained, as shown in Figure 4 .

It can be seen, from Figure 4, that the cumulative distribution curve of the diameter is in good agreement with the fitted normal distribution curve. Therefore, the probability distribution model of the diameter of the direct shear specimen can be obtained, as shown in

$$
d \sim N(61.691,0.0401) \text {. }
$$

3.2. Generation of a Random Number and Random Sampling. The probability distribution of the three parameters is used to generate random numbers. The vertical forces applied in the test are $100 \mathrm{kPa}, 200 \mathrm{kPa}, 300 \mathrm{kPa}$, and $400 \mathrm{kPa}$. According to formula (1), four groups of random numbers of vertical forces are generated. According to formula (2), a random number is also generated for each group of horizontal forces. According to formula (3), a set of random numbers is generated for the specimen diameter $d$. Since the confidence interval can be reduced by increasing the number of repeated simulations [42], the above random numbers are all 1000 . 


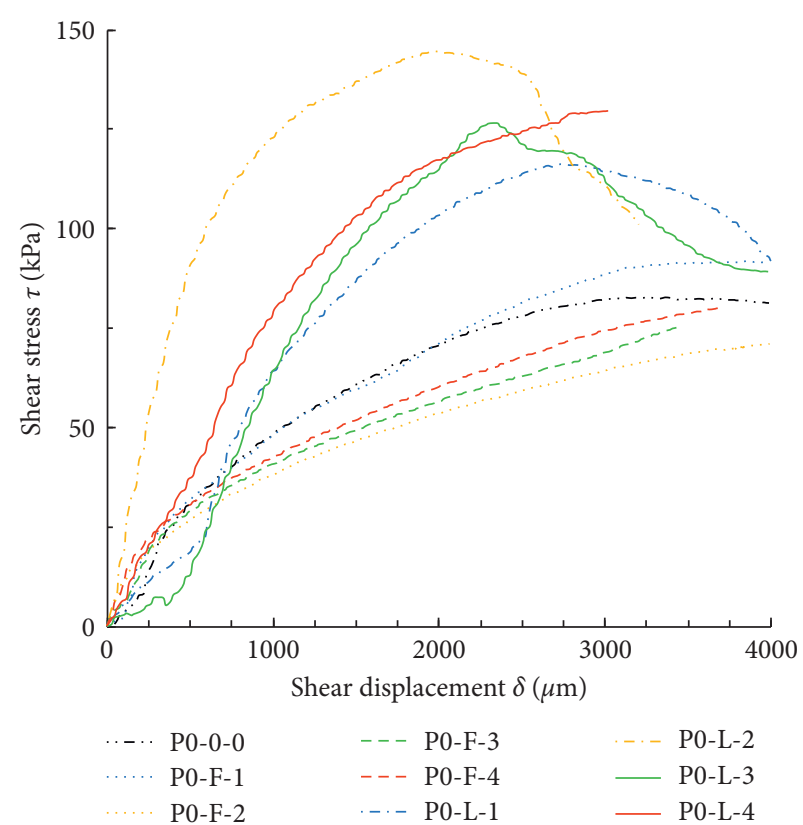

(a)

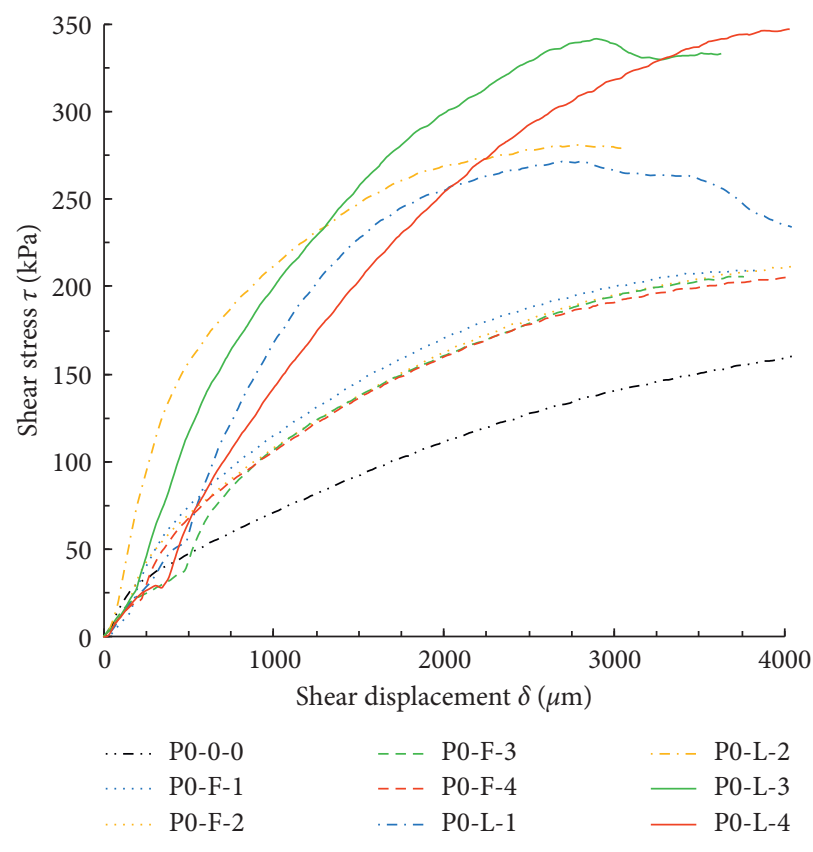

(c)

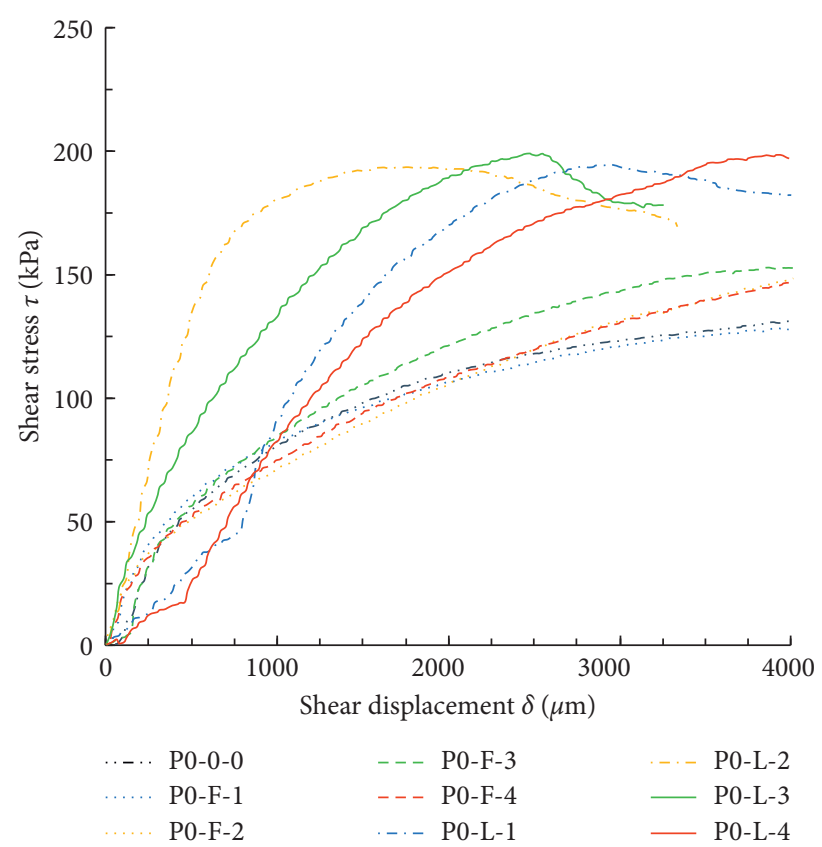

(b)

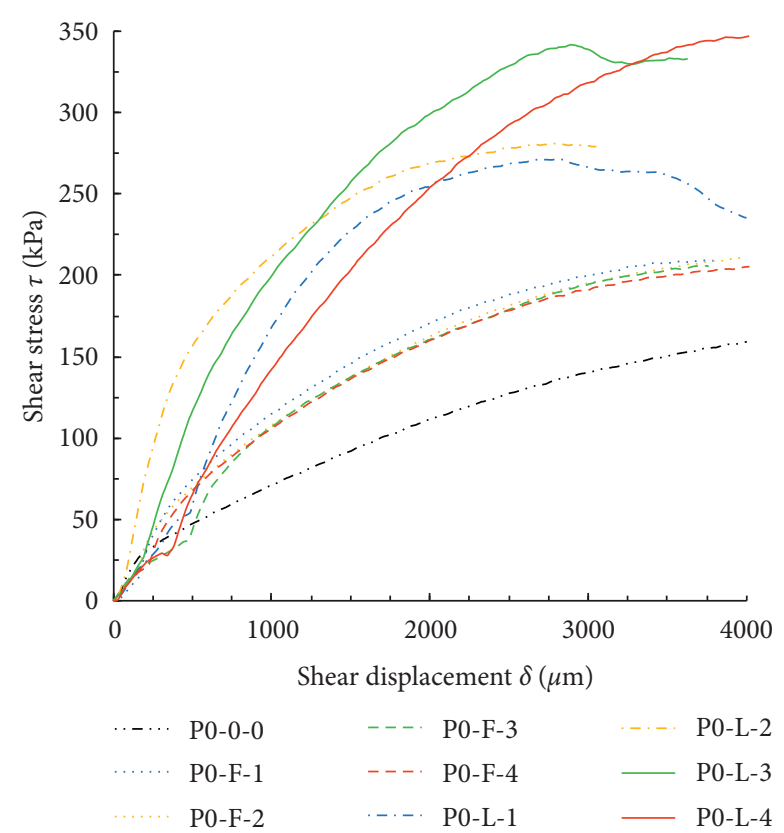

(d)

Figure 1: $\tau \delta$ curves of the modified iron tailings with the 0 freeze-thaw cycle: (a) $100 \mathrm{kPa}$ normal stress, (b) $200 \mathrm{kPa}$ normal stress, (c) $300 \mathrm{kPa}$ normal stress, and (d) $400 \mathrm{kPa}$ normal stress.

Taking diameter $d$ as an example, the random sampling steps are as follows:

(a) Put 1000 random data generated according to formula (3) in vector $D ; D$ is a vector of 1 row and 1000 columns.

(b) According to formula (4), the random number $n$ can be calculated. $n$ is a natural number between 1 and 1000:

$$
n=1+\operatorname{int}(\operatorname{rand}() * 999) .
$$

(c) Let $d i=D(n)$; this completes the $i$-th random sampling.

The sampling results of $\mathrm{F}$ and $\mathrm{t}$ can be obtained by the same method. The number of random numbers and the number of cycle calculations are taken as 1000 times. 


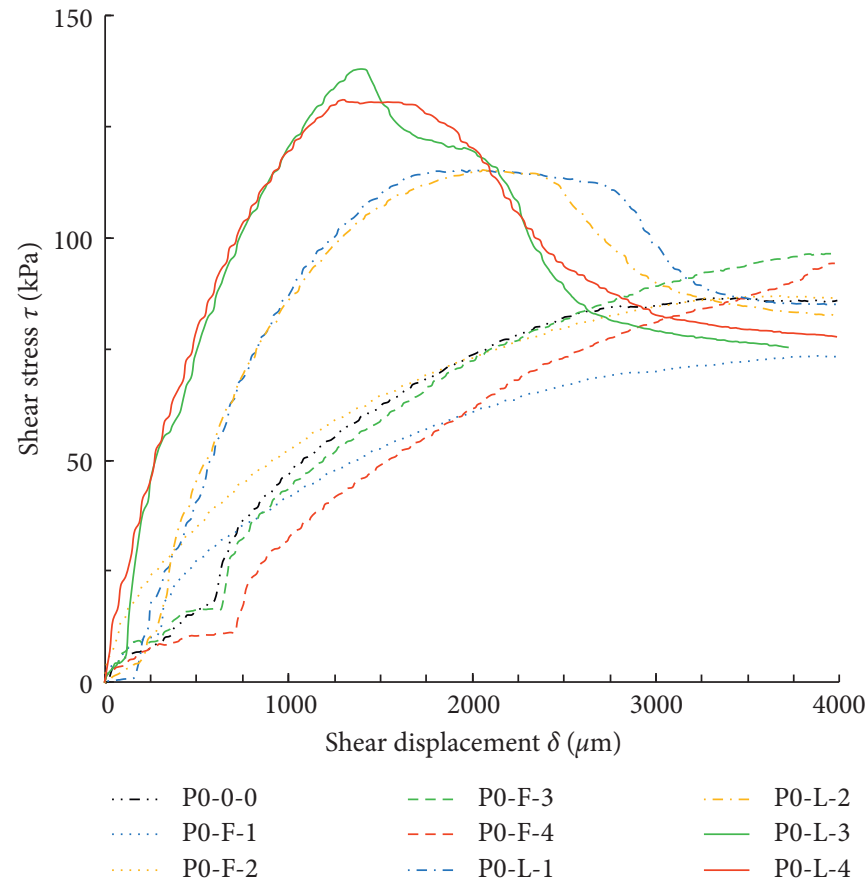

(a)

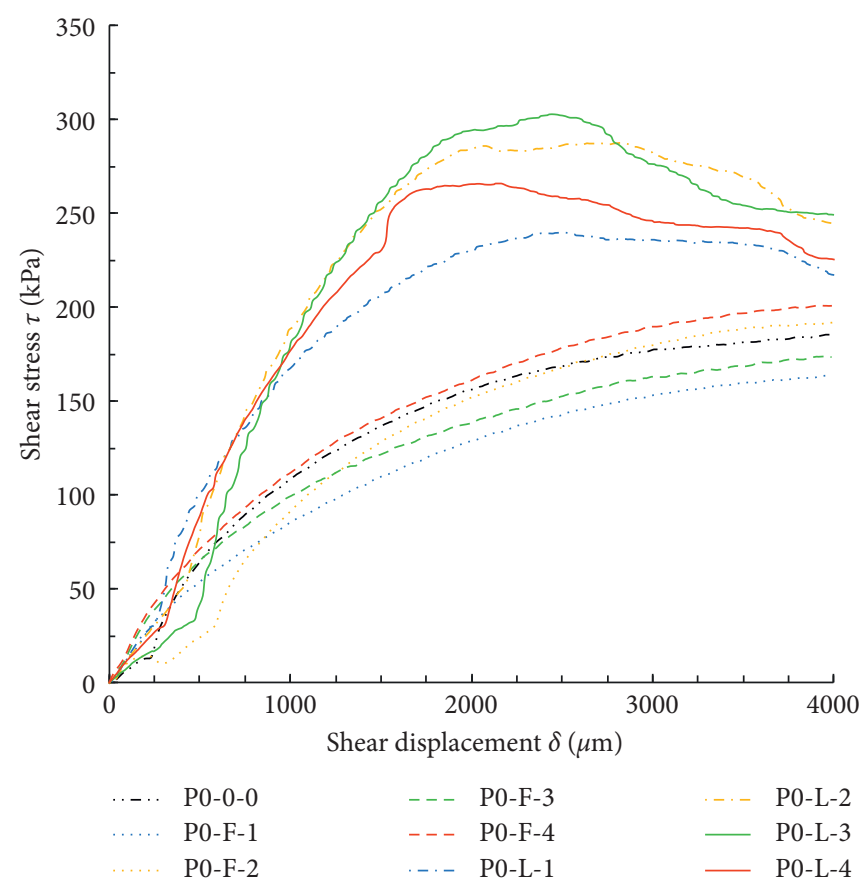

(c)

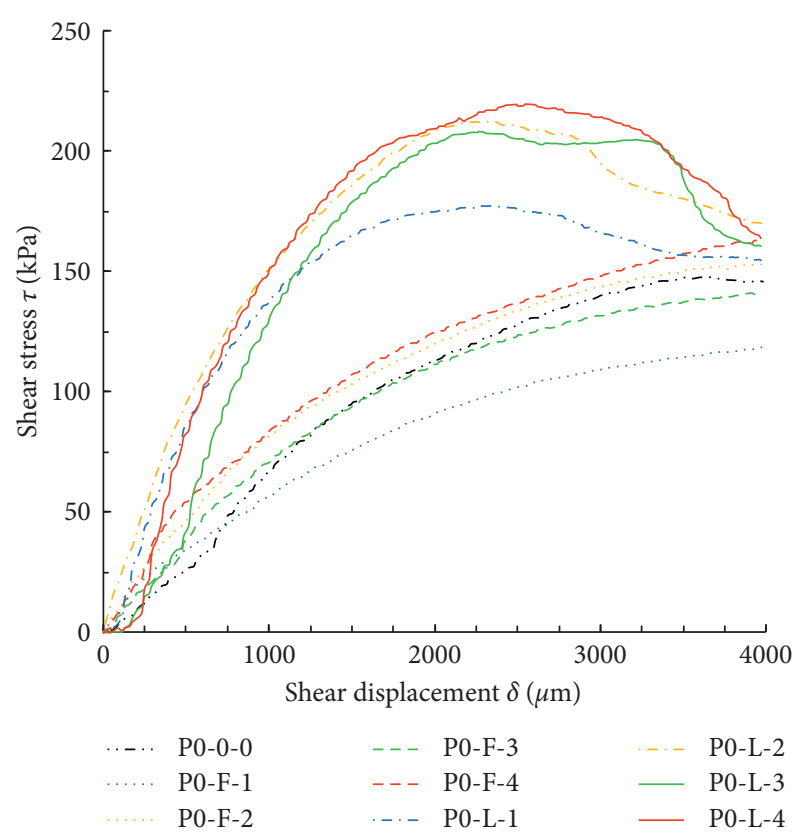

(b)

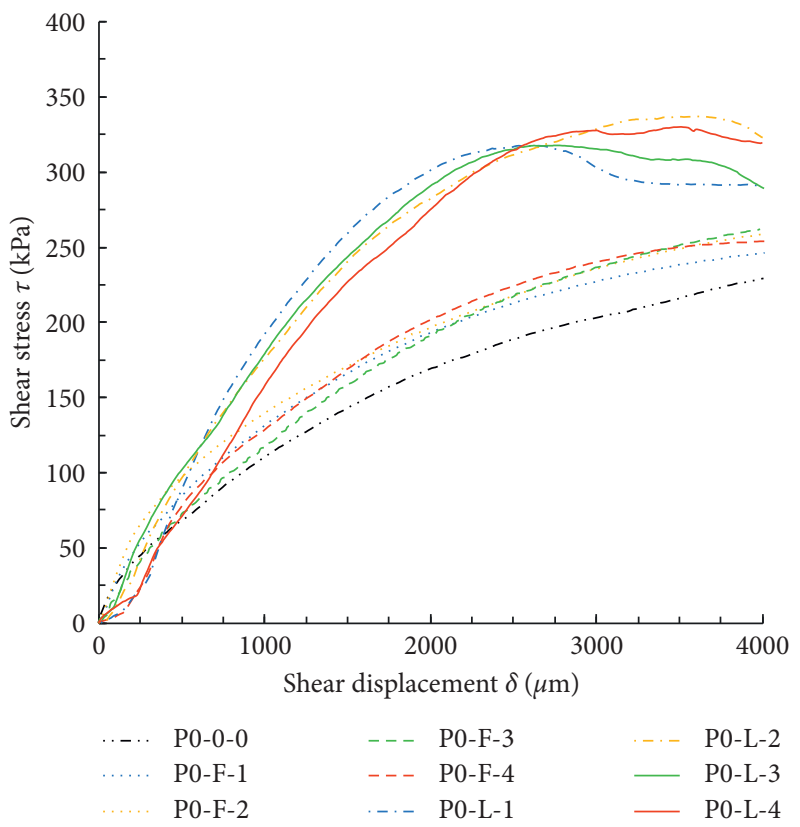

(d)

FIgURe 2: $\tau$ - $\delta$ curves of the modified iron tailings with the 1 freeze-thaw cycle: (a) $100 \mathrm{kPa}$ normal stress, (b) $200 \mathrm{kPa}$ normal stress, (c) $300 \mathrm{kPa}$ normal stress, and (d) $400 \mathrm{kPa}$ normal stress.

3.3. $c$ and $\varphi$ Calculation. To obtain a more accurate probability distribution of $c$ and $\varphi$, the number of Monte Carlo simulations is changed to 1000 . A number for $d, F$, and $T$ is taken randomly from each group, and $c$ and $\varphi$ of the modified iron tailings are calculated. The specific steps are as follows:

(1) The sample area $A$ is calculated according to

$$
A=\frac{\pi d^{2}}{4}
$$

where $d$ is the randomly selected diameter value of the sample. 
TABLE 2: $c$ and $\varphi$ values of each group of samples.

\begin{tabular}{lcc}
\hline Number & $c(\mathrm{kPa})$ & $\varphi\left(^{\circ}\right)$ \\
\hline P0-0-0 & 12.3 & 31.7 \\
P0-F-1 & 31.9 & 29.3 \\
P0-F-2 & 22.3 & 31.9 \\
P0-F-3 & 15.6 & 33.5 \\
P0-F-4 & 22.1 & 32.4 \\
P0-L-1 & 41.5 & 38.0 \\
P0-L-2 & 76.7 & 33.9 \\
P0-L-3 & 92.9 & 36.0 \\
P0-L-4 & 36.4 & 43.0 \\
P1-0-0 & 37.0 & 27.8 \\
P1-F-1 & 14.0 & 29.6 \\
P1-F-2 & 32.3 & 29.4 \\
P1-F-3 & 32.3 & 30.0 \\
P1-F-4 & 54.7 & 27.3 \\
P1-L-1 & 48.8 & 33.9 \\
P1-L-2 & 51.6 & 37.0 \\
P1-L-3 & 87.4 & 34.8 \\
P1-L-4 & 77.7 & 34.6 \\
\hline
\end{tabular}

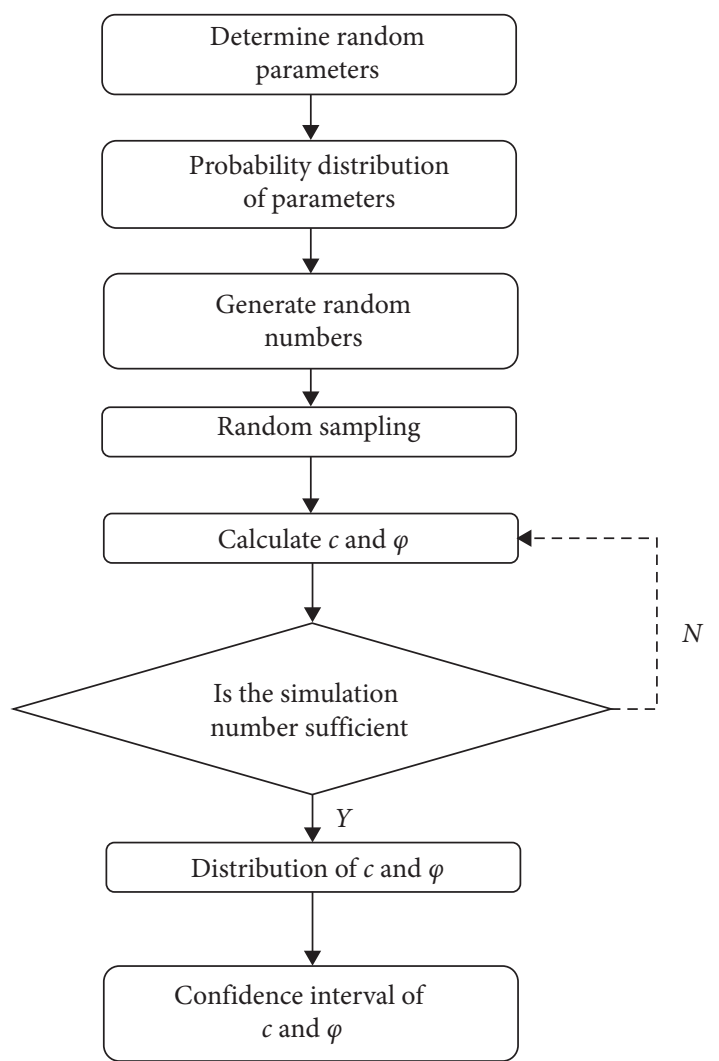

Figure 3: Calculation flow chart of the Monte Carlo method.

(2) The normal stress $p(i)$ is calculated according to

$$
p(i)=\frac{F(i)}{A},
$$

where $F(i)$ is the random number of the applied vertical forces, $i=1,2,3,4$.
(3) The shear stress $t(i)$ is calculated according to

$$
\tau(i)=\frac{T(i)}{A},
$$

where, $\tau(i)$ is the random number of the applied horizontal forces, $i=1,2,3,4$.

(4) The $c$ and $\varphi$ values of the modified iron tailings are calculated.

According to the Mohr-Coulomb theory, the normal stress $p$ and the shear stress $\tau$ satisfy a linear relationship. Therefore, $c$ and $\varphi$ can be calculated according to the least squares method. The calculation process is shown in

$$
\begin{aligned}
\bar{\tau} & =\frac{\sum_{i=1}^{n} \tau i}{n}, \\
\bar{p} & =\frac{\sum_{i=1}^{n} p i}{n}, \\
\tan (\varphi) & =\frac{\sum_{i=1}^{n} \tau i p i-\left(\sum_{i=1}^{n} \tau i \sum_{i=1}^{n} p i / n\right)}{\sum_{i=1}^{n} \tau i^{2}-\left(\left(\sum_{i=1}^{n} \tau i\right)^{2} / n\right)}, \\
c & =\bar{p}-\tan (\varphi) \bar{p},
\end{aligned}
$$

where $\bar{\tau}$ and $\bar{p}$ are the mean values of $\tau$ and $p$, respectively, $i=1,2,1000$ and $n=1000$.

According to the above calculation process, the $c$ and $\varphi$ calculation results of the modified iron tailings can be obtained.

3.4. Probability Distribution Characteristics of $c$ and $f$. The $c$ and $\varphi$ values of various proportions of the modified iron tailings are calculated by the Monte Carlo method, and the cumulative distribution images of different proportions under the 0 freeze-thaw state and the 1 freeze-thaw state are drawn, as shown in Figures 5 and 6, respectively.

It can be seen, from Figures 5 and 6 , that the $c$ and $\varphi$ values of the modified iron tailings obey a normal distribution through the Monte Carlo simulation.

3.5. Confidence Interval of $c$ and $\varphi$. The confidence interval shows the degree to which the real value has a certain probability of falling around the measurement results, which indicates the degree of reliability of the measured results. The reliability of the test data is judged by calculating the confidence interval of $c$ and $\varphi$. If the significance level is 0.05 , the confidence level is $0.95 \%$. The confidence interval of $c$ and $\varphi$ is calculated as follows:

(1) The average error is calculated according to

$$
a_{e}=\frac{\sigma}{\sqrt{n}}
$$




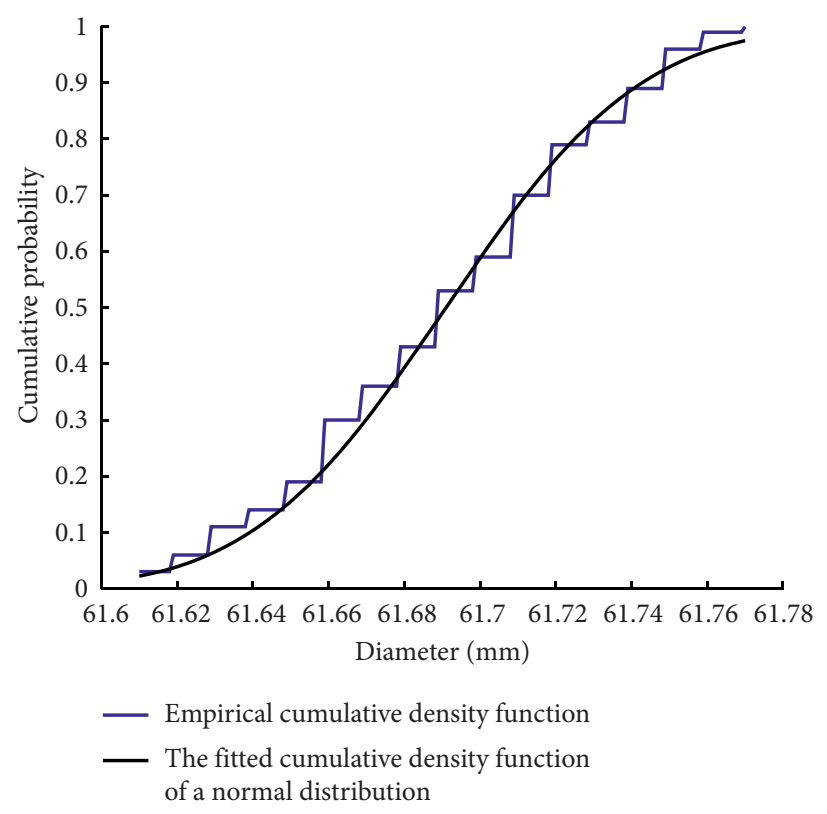

FIGURE 4: The cumulative distribution curve of the specimen diameter.

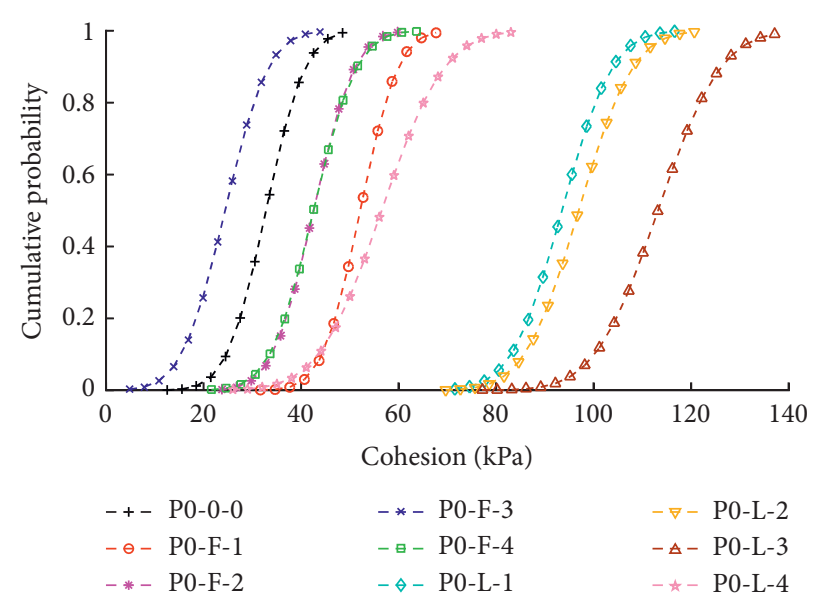

(a)

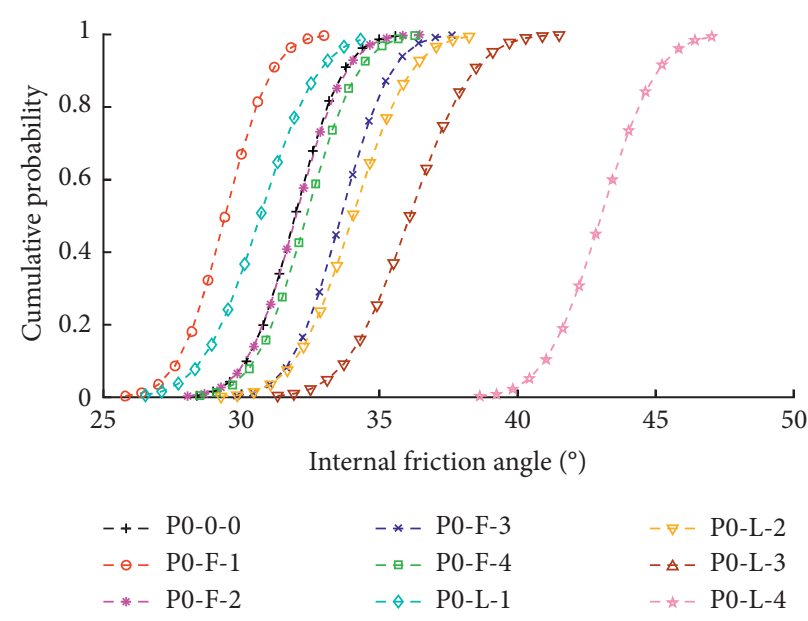

(b)

FIGURE 5: Cumulative probability distribution of the $c$ and $\varphi$ of the modified iron tailings with the 0 freeze and thaw cycle: (a) a cumulative distribution image of the cohesion $c$ in different proportions and (b) a cumulative distribution image of the internal friction angle $\varphi$.

where $n$ is the number of data; $\sigma$ is the standard deviation; and $a_{e}$ is the average error.

(2) The error range is calculated according to

$$
e=t a_{e},
$$

where $e$ is the error range and $t$ is the double quantile of the $t$ distribution, which can be obtained by looking up the quantile table of the $t$ distribution.

(3) The confidence interval is calculated according to following formulas:

$$
\begin{aligned}
& z_{1}=\mu-e, \\
& z_{2}=\mu+e,
\end{aligned}
$$

where $\mu$ is the sample mean; $z_{1}$ is the lower limit of the confidence interval; and $z_{2}$ is the upper limit of the confidence interval.

The confidence interval of $c$ and $\varphi$ is calculated through the above steps, and then a box line diagram showing the change of the content of the modified material is drawn, as shown in Figure 7 and 8. 


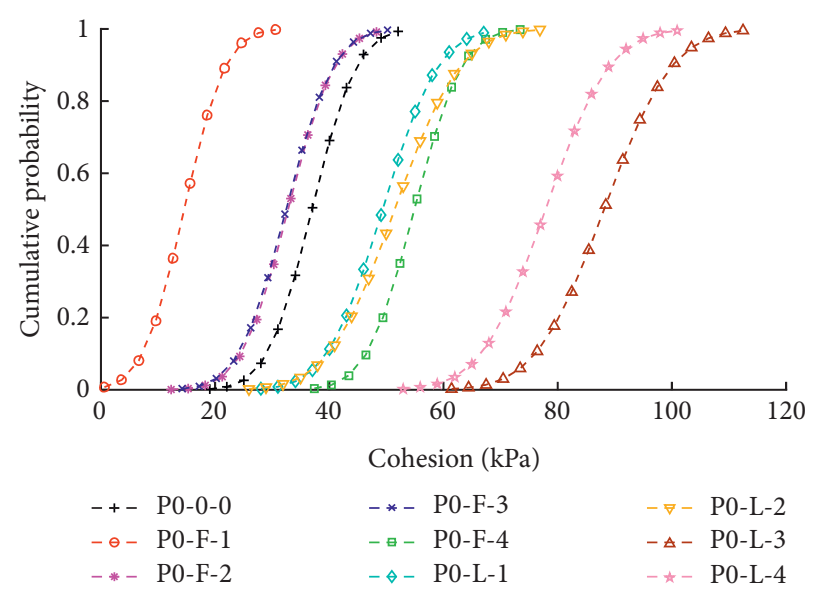

(a)
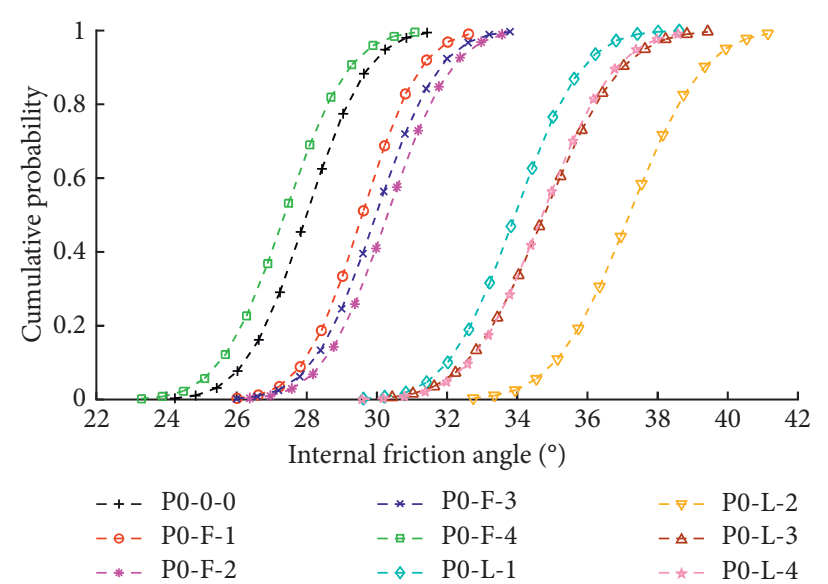

(b)

Figure 6: Cumulative probability distribution of the $c$ and $\varphi$ of the modified iron tailings with the one freeze and thaw cycle. (a) A cumulative distribution image of the cohesion $c$ and (b) a cumulative distribution image of the internal friction angle $\varphi$.

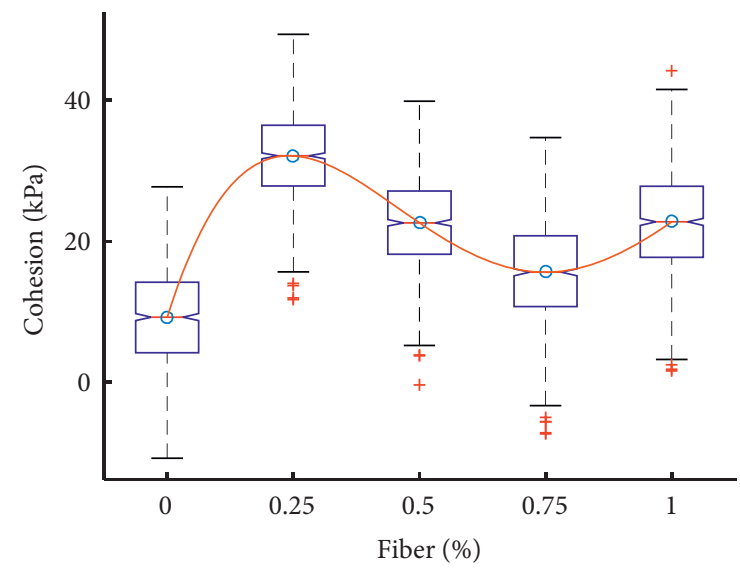

(a)

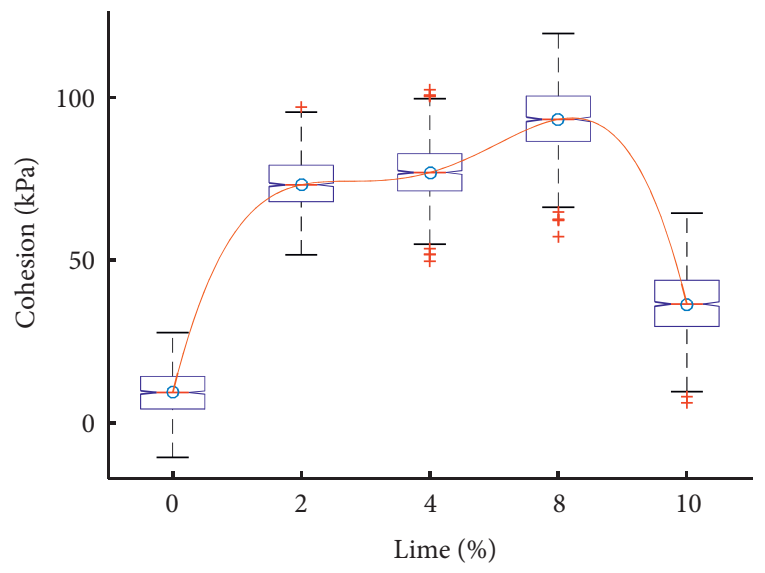

(c)

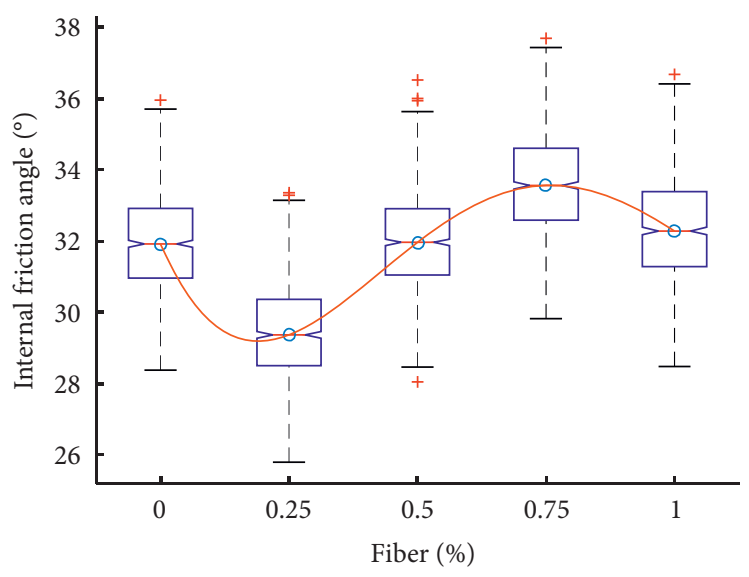

(b)

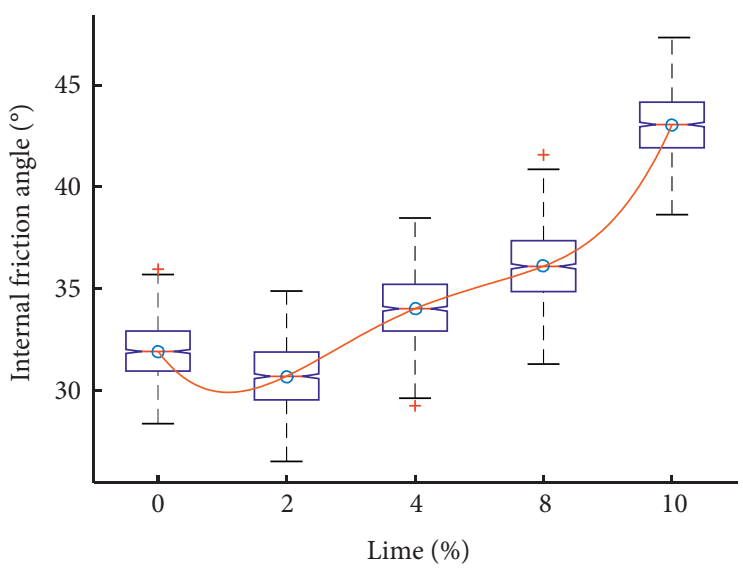

(d)

Figure 7: The change trend of the confidence interval of $c$ and $\varphi$ of the modified iron tailings with the 0 freeze and thaw cycle: (a) the confidence interval of $c$ varies with the fiber content, (b) the confidence interval of $\varphi$ varies with the fiber content, (c) the confidence interval of $c$ varies with the lime content, and (d) the confidence interval of $\varphi$ varies with the lime content. 


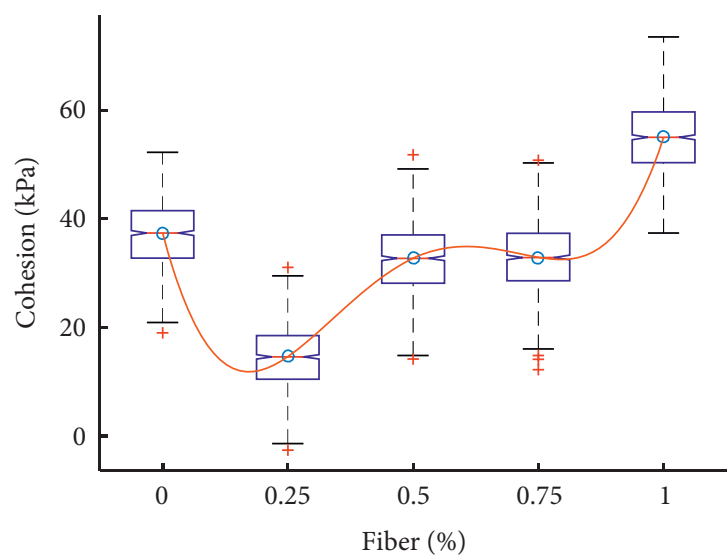

(a)

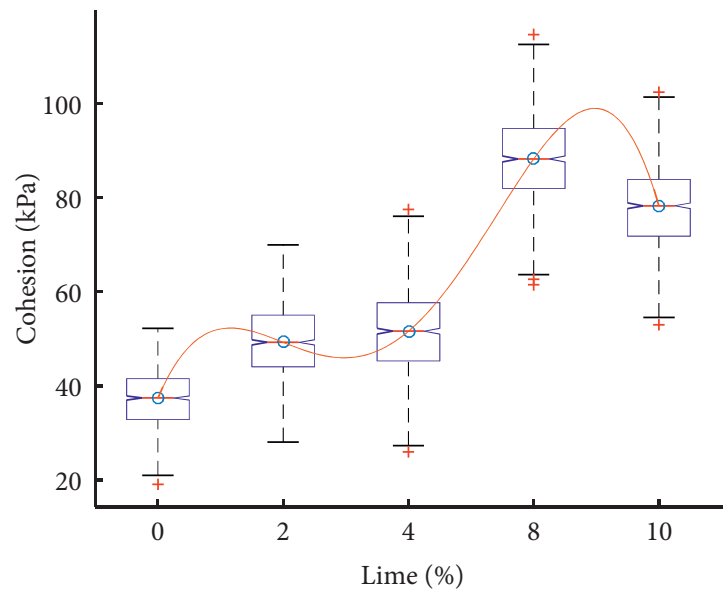

(c)

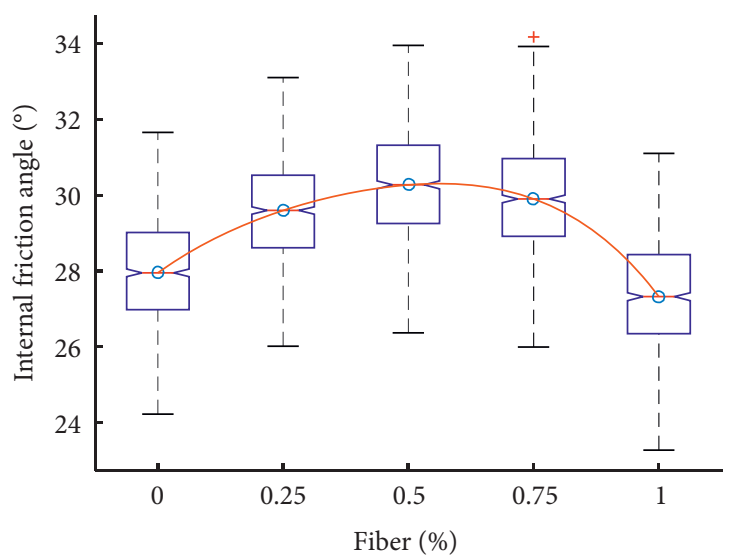

(b)

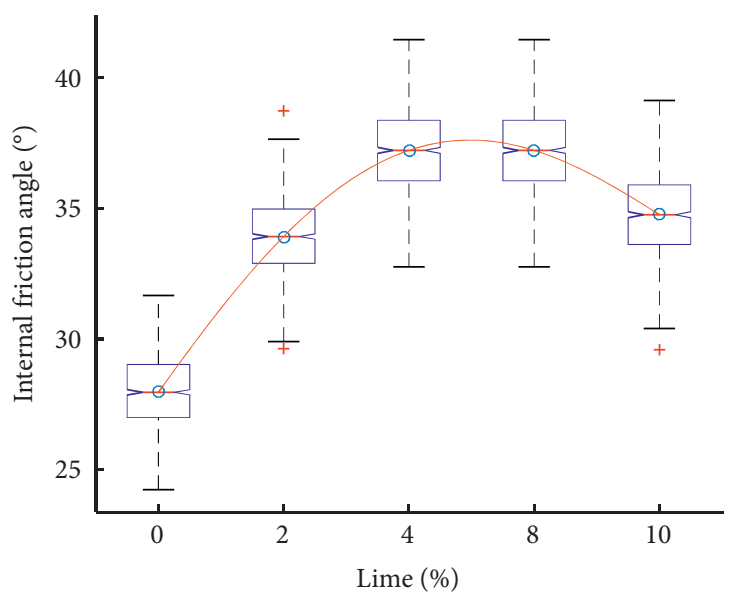

(d)

Figure 8: The change trend of the confidence interval of $c$ and $\varphi$ of the modified iron tailings with the one freeze and thaw cycle: (a) the confidence interval of $c$ varies with the fiber content, (b) the confidence interval of $\varphi$ varies with the fiber content, (c) the confidence interval of $c$ varies with the lime content, and (d) the confidence interval of $\varphi$ varies with the lime content.

As for the modified iron tailing with the 0 freeze and thaw cycle, from Figure 7, it can be seen that the cohesion $c$ of the fiber-modified iron tailings first increases and then decreases with the increase of the fiber content. When the fiber content is $0.25 \%, c$ reaches the maximum. The value of the internal friction angle $\varphi$ first decreases and then increases with the increase of the fiber content. When the fiber content is $0.75 \%$, the value of $\varphi$ reaches the maximum. The cohesion $c$ value of the lime-modified iron tailings first increases and then decreases with the increase of the lime content. When the lime content is $8 \%$, the cohesion $c$ value reaches the maximum, and the internal friction angle $\varphi$ value increases with the increase of the lime content.

When the modified iron tailing is in the one freeze-thaw cycle, it can be seen, from Figure 8, that the cohesion $c$ of the fiber-modified iron tailings first decreases and then increases with the increase of the fiber content. When the fiber content is $0.25 \%, c$ reaches the minimum. The internal friction angle $\varphi$ first increases and then decreases with the increase of the fiber content, and it reaches the maximum when the fiber content is $0.5 \%$. The cohesion $c$ of the lime-modified iron tailing first increases and then decreases with the increase of the lime content, and it reaches the maximum when the lime content is $8 \%$. The internal friction angle $\varphi$ first increases and then decreases with the increase of the lime content, and it reaches the maximum when the lime content is $4 \%$.

Comparing the confidence intervals of $c$ and $\varphi$ of each group of samples in Table 2 with those in Figures 7 and 8, it is found that the experimental values in Table 2 are all within the confidence interval, which indicates that the direct shear test results have a $95 \%$ reliability. It can be seen, from Table 2, that the effect of the freeze-thaw cycle on the cohesion of modified iron tailings is obvious, but not on the internal friction angle. Considering the change of the cohesion and internal friction angle after the freeze-thaw cycle, it can be concluded that fiber-modified iron tailings with a fiber content of $1 \%$ and lime-modified iron tailings with a lime content of $8 \%$ have the best frost resistance.

\section{Conclusions}

Through a direct shear test, the shear characteristics of fiberand lime-modified iron tailings, under the action of a freezethaw cycle, are analyzed, and the uncertainty factors associated with direct shear tests are simulated by the Monte Carlo algorithm, and the following three conclusions can be obtained: 
(1) The $\tau$ - $\delta$ curves of fiber-modified iron tailings and lime-modified iron tailings are not affected by the freeze-thaw cycles. The $\tau-\delta$ curves of fiber-modified iron tailings are a hardening-type curve, and the peak value of the stress is produced when the shear displacement reaches $4 \mathrm{~mm}$. The $\tau$ - $\delta$ curve of limemodified iron tailings is a softening-type curve. With the increase of the shear displacement, the shear stress first increases to the peak value and then decreases gradually, and with the increase of the normal stress, the maximum shear stress increases gradually.

(2) In the direct shear test, the main uncertainty factors are the specimen diameter, vertical force, and horizontal force. The diameter $d$ of the sample obeys a normal distribution. The vertical force $F$ and the horizontal force Tobey a uniform distribution. $c$ and $\varphi$ calculated by the Monte Carlo method obey a normal distribution. In this direct shear test, the $c$ and $\varphi$ values of each group of modified iron tailings achieve a 95\% confidence level.

(3) Through the Monte Carlo simulation, it can be concluded that, under a 95\% confidence condition, the cohesion of fibers to iron tailings is obvious, but the internal friction angle is not obvious. The cohesion and internal friction angle of iron tailings are clearly improved by lime. The effect of the freeze-thaw cycle on the cohesion of modified iron tailings is obvious, but not on the internal friction angle. Additionally, the fiber-modified iron tailings with a $1 \%$ fiber content and lime-modified iron tailings with an $8 \%$ lime content have the best frost resistance.

\section{Data Availability}

The data used to support the findings of this study are available from the corresponding author upon request.

\section{Conflicts of Interest}

The authors declare no conflicts of interest.

\section{Authors' Contributions}

N. L. proposed the idea; J. Q. conducted the tests and analyzed the data; P. J. wrote and revised the manuscript; and W. W. and N. L. reviewed the results and approved the final version of the manuscript.

\section{Acknowledgments}

This research was funded by the National Natural Science Foundation of China (Grant no. 41772311), the Zhejiang Provincial Natural Science Foundation of China (Grant no. Q20E080042), and the Open Research Fund of State Key Laboratory of Geomechanics and Geotechnical Engineering,
Institute of Rock and Soil Mechanics, Chinese Academy of Science (Grant no. Z017013).

\section{References}

[1] C. Li, H. Sun, J. Bai, and L. Li, "Innovative methodology for comprehensive utilization of iron ore tailings," Journal of Hazardous Materials, vol. 174, no. 1-3, pp. 71-77, 2010.

[2] N. Li, S. Lv, W. Wang, J. Guo, P. Jiang, and Y. Liu, "Experimental investigations on the mechanical behavior of iron tailings powder with compound admixture of cement and nano-clay," Construction and Building Materials, vol. 254, Article ID 119259, 2020.

[3] P. Jiang, S. W. Lv, Y. Wang, N. Li, and W. Wang, "Investigation on direct shear and energy dissipation characteristics of iron tailings powder reinforced by polypropylene fiber," Applied Science, vol. 9, pp. 1-15, 2019.

[4] L. Hu, H. Wu, L. Zhang, P. Zhang, and Q. Wen, "Geotechnical properties of mine tailings," Journal of Materials in Civil Engineering, vol. 29, Article ID 04016220, 2016.

[5] C. Li, H. Sun, Z. Yi, and L. Li, "Innovative methodology for comprehensive utilization of iron ore tailings," Journal of Hazardous Materials, vol. 174, no. 1-3, pp. 78-83, 2010.

[6] G. Young and M. Yang, "Preparation and characterization of Portland cement clinker from iron ore tailings," Construction and Building Materials, vol. 197, pp. 152-156, 2019.

[7] A. U. Shettima, M. W. Hussin, Y. Ahmad, J. Mirza, and J. Mirza, "Evaluation of iron ore tailings as replacement for fine aggregate in concrete," Construction and Building Materials, vol. 120, pp. 72-79, 2016.

[8] Z. Zhu, B. Li, and M. Zhou, "The influences of iron ore tailings as fine aggregate on the strength of ultra-high performance concrete," Advances in Materials Science and Engineering, vol. 2015, pp. 1-6, 2015.

[9] S. Zhao, J. Fan, and W. Sun, "Utilization of iron ore tailings as fine aggregate in ultra-high performance concrete," Construction and Building Materials, vol. 50, pp. 540-548, 2014.

[10] X. Lv, W. Shen, L. Wang, Y. Dong, J. Zhang, and Z. Xie, "A comparative study on the practical utilization of iron tailings as a complete replacement of normal aggregates in dam concrete with different gradation," Journal of Cleaner Production, vol. 211, pp. 704-715, 2019.

[11] H.-N. Li, P.-F. Liu, C. Li, G. Li, and H. Zhang, "Experimental research on dynamic mechanical properties of metal tailings porous concrete," Construction and Building Materials, vol. 213, pp. 20-31, 2019.

[12] F. Han, S. Song, J. Liu, and S. Huang, "Properties of steamcured precast concrete containing iron tailing powder," Powder Technology, vol. 345, pp. 292-299, 2019.

[13] W. C. Fontes, J. C. Mendes, S. N. D. Silva, and R. A. F. Peixoto, "Mortars for laying and coating produced with iron ore tailings from tailing dams," Construction and Building Materials, vol. 112, pp. 988-995, 2016.

[14] R. K. Etim, A. O. Eberemu, and K. J. Osinubi, "Stabilization of black cotton soil with lime and iron ore tailings admixture," Transportation Geotechnics, vol. 10, pp. 85-95, 2017.

[15] L. A. C. Bastos, G. C. Silva, J. C. Mendes, and R. A. F. Peixoto, "Using iron ore tailings from tailing dams as road material," Journal of Materials in Civil Engineering, vol. 28, Article ID 04016102, 2016.

[16] X. Wang, H. Zhan, J. Wang, and P. Li, "On the mechanical damage to tailings sands subjected to dry-wet cycles," Bulletin of Engineering Geology and the Environment, vol. 78, no. 6, pp. 4647-4657, 2019. 
[17] P. Jiang, L. Qiu, N. Li, W. Wang, A. Zhou, and J. Xiao, "Shearing performance of lime-reinforced iron tailing powder based on energy dissipation," Advances in Civil Engineering, vol. 2018, Article ID 4748526, 8 pages, 2018.

[18] R. Chen, W. Lei, and Z. Li, "Anisotropic shear strength characteristics of a tailings sand," Environmental Earth Sciences, vol. 71, no. 12, pp. 5165-5172, 2014.

[19] Y. Chen, Z. Wei, M. Irfan, J. Xu, and Y. Yang, "Laboratory investigation of the relationship between electrical resistivity and geotechnical properties of phosphate tailings," Measurement, vol. 126, pp. 289-298, 2018.

[20] Q. Jin and B. Li, "Effects of lime treatment on the geotechnical properties of dredged mud," Marine Georesources \& Geotechnology, vol. 37, no. 9, pp. 1083-1094, 2019.

[21] M. Tajdini, M. Hajialilue Bonab, and S. Golmohamadi, "An experimental investigation on effect of adding natural and synthetic fibres on mechanical and behavioural parameters of soil-cement materials," International Journal of Civil Engineering, vol. 16, no. 4, pp. 353-370, 2018.

[22] A. H. Vakili, J. Ghasemi, M. R. bin Selamat, M. Salimi, and M. S. Farhadi, "Internal erosional behaviour of dispersive clay stabilized with lignosulfonate and reinforced with polypropylene fiber," Construction and Building Materials, vol. 193, pp. 405-415, 2018.

[23] K. Thermann, C. Gau, and J. Tiedemann, "Shear strength parameters from direct shear tests-influencing factors and their significance," The Geological Society of London, vol. 484, pp. 1-12, 2006.

[24] Y. Liu, E. J. Chen, S.-T. Quek, J.-T. Yi, and F.-H. Lee, "Effect of spatial variation of strength and modulus on the lateral compression response of cement-admixed clay slab," Géotechnique, vol. 65, no. 10, pp. 851-865, 2015.

[25] K. Yao, D. An, W. Wang, N. Li, C. Zhang, and A. Zhou, "Effect of nano-mgo on mechanical performance of cement stabilized silty clay," Marine Georesources \& Geotechnology, vol. 38, no. 2, pp. 250-255, 2020.

[26] W. Wang, N. Li, F. Zhang, A. Zhou, and S. Chi, "Experimental and mathematical investigations on unconfined compressive behaviour of costal soft soil under complicated freezing processes," Polish Maritime Research, vol. 23, no. 4, pp. 112-116, 2016.

[27] K. Yao, N. Li, D.-H. Chen, and W. Wang, "Generalized hyperbolic formula capturing curing period effect on strength and stiffness of cemented clay," Construction and Building Materials, vol. 199, pp. 63-71, 2019.

[28] W. Wang, C. Zhang, N. Li, F. Tao, and K. Yao, "Characterisation of nano magnesia-cement-reinforced seashore soft soil by direct-shear test," Marine Georesources \& Geotechnology, vol. 37, no. 8, pp. 989-998, 2019.

[29] W. Wang, Y. Li, K. Yao, N. Li, A. Zhou, and C. Zhang, "Strength properties of nano-MgO and cement stabilized coastal silty clay subjected to sulfuric acid attack," Marine Georesources \& Geotechnology, vol. 3, pp. 1-10, 2019.

[30] Y. Pan, Y. Liu, F. H. Lee, and K. K. Phoon, "Analysis of cement-treated soil slab for deep excavation support - a rational approach," Géotechnique, vol. 69, no. 10, pp. 888-905, 2019.

[31] Y. Liu, Y. Pan, M. Sun, J. Hu, and K. Yao, "Lateral compression response of overlapping jet-grout columns with geometric imperfections in radius and position," Canadian Geotechnical Journal, vol. 55, no. 9, pp. 1282-1294, 2018.

[32] Y. Pan, Y. Liu, A. Tyagi, F.-H. Lee, and D.-Q. Li, "Modelindependent strength-reduction factor for effect of spatial variability on tunnel with improved soil surrounds," Géotechnique, vol. 32, pp. 1-17, 2020.

[33] J. B. Cardoso, J. R. de Almeida, J. M. Dias, and P. G. Coelho, "Structural reliability analysis using Monte Carlo simulation and neural networks," Advances in Engineering Software, vol. 39, no. 6, pp. 505-513, 2008.

[34] W. Wang, Y. Fu, C. Zhang, N. Li, and A. Zhou, "Mathematical models for stress-strain behavior of nano magnesia-cementreinforced seashore soft soil," Mathematics, vol. 8, no. 3, p. 456, 2020.

[35] Y. Pan, J. Yi, S.-H. Goh, J. Hu, W. Wang, and Y. Liu, “A threedimensional algorithm for estimating water-tightness of cement-treated ground with geometric imperfections," Computers and Geotechnics, vol. 115, p. 103176, 2019.

[36] Y. Liu, W. Zhang, L. Zhang, Z. Zhu, J. Hu, and H. Wei, "Probabilistic stability analyses of undrained slopes by 3D random fields and finite element methods," Geoscience Frontiers, vol. 9, no. 6, pp. 1657-1664, 2018.

[37] Chinese code. Standard for geotechnical testing method (GB/ T 50123-2019).

[38] G. Chen, X. Wang, R. Wang, and G. Liu, "Health risk assessment of potentially harmful elements in subsidence water bodies using a Monte Carlo approach: an example from the Huainan coal mining area, China," Ecotoxicology and Environmental Safety, vol. 171, pp. 737-745, 2019.

[39] V. R. Meyer, "Measurement uncertainty," Journal of Chromatography A, vol. 1158, no. 1-2, pp. 15-24, 2007.

[40] S. M. Ross, Introduction to Probability and Statistics for Engineers and Scientists, Elsevier, Amsterdam, Netherlands, 2004.

[41] Y. Liu, Y. J. Jiang, H. Xiao, and F. H. Lee, "Determination of representative strength of deep cement-mixed clay from core strength data," Géotechnique, vol. 67, no. 4, pp. 350-364, 2017.

[42] S. J. Kamat and M. W. Riley, "Determination of reliability using event-based Monte Carlo simulation," IEEE Transactions on Reliability, vol. R-24, no. 1, pp. 73-75, 1975. 